it was felt desirable to await the publication of the Forestry Commission's plans before deciding on some aspects of the future teaching and research organization at the Institute. If the stress in the report appears to be on the importance of closer co-operation in research with the Forestry Commission, this was only because there appeared to be room for it, whereas decisions affecting Colonial forestry had already been agreed. The expected White Paper has since been published; it was considered by the University Committee for Forestry, which found that no further changes in its own plans were necessitated.

This opportunity may be taken to add that forestry has recently been made an Honour School in this University, as from the next academic year; two years study of biological and physical science will normally be required before the two years forestry courses are undertaken, as was already the position under the statute of 1938 .

Imperial Forestry Institute,

H. G. Champion.

Oxford. Aug. 21.

\section{Structure of Cellulose}

IN their criticism of my suggested structure of cellulose ${ }^{1}$, Astbury and Davies ${ }^{2}$ appealed to evidence not then available to me in a thesis by Dr. C. J. Brown $^{3}$. My thanks are due to Dr. Astbury for bringing this interesting work to notice and to Dr. Brown for the opportunity to read it. I do not think that it settles the issue between the angles $110^{\circ}$ and $90^{\circ}$ at the oxygen of the pyranose ring. The difference amounts to $\pm 0.15 \mathrm{~A}$. in the $b$ co-ordinate of $\mathrm{Cl}$ and C5 respectively, whereas the author, rather modestly, claims only an accuracy of $\pm 0.4 \mathrm{~A}$. The features referred to by Astbury and Davies describe a regular six-sided figure-I presume they would not suggest that this is a precise description.

In "the most detailed saccharide crystal analysis so far reported", Cox and Jeffery ${ }^{4}$ conclude in favour of a slightly flattened form of the Sachsetrans form. This is the form I adopt and, moreover, the strainless arm-chair form, though Dr. Astbury does not appear to recognize it nor appreciate its comfort. In these, as in other studies, reasonable agreement is found with forms based on the $110^{\circ}$ assumption, but it remains to be proved that the error in a trial of $90^{\circ}$ must be significantly greater.

Meyer and Misch ${ }^{5}$ also assume $110^{\circ}$, but I cannot reproduce their parameters from their geometrical assumptions. A unit of length to fit into the $10 \cdot 3 \mathrm{~A}$. identity period can be obtained by assuming a regular ring of bonds of length $1.50 \mathrm{~A}$. (mean of $4 \mathrm{C}-\mathrm{C}$ and $2 \mathrm{C}-\mathrm{O}$ bonds) but this is too crude an approximation. My calculations of the rigorous form, with the screw axis as shown by Meyer and Misch, give a length of 11.12 A. (Curiously enough this is longer than it.would be if the ring were a regular figure of 1.54 A. bonds.) With another choice of axis, the chain might be buckled into the cell, but I have been unable to find a probable form in conformity with the geometry and with the elearest features of the $\mathrm{X}$-ray diffraction, from the $\left(\begin{array}{lll}h & 0 & l\end{array}\right)$ zone.

$\mathrm{Cox}^{6}$ recognizes that the form of the molecule may be modified by intermolecular forces. This consideration should modify any dogmatism about the unknown form of the cellulose ring; but it does not seriously affect the power of his elegant argument for a nearly co-planar arrangement of the sugar ring carbons?.
It must be admitted that direct evidence to decide between $90^{\circ}$ and $110^{\circ}$ for the oxygen angle in the cellulose ring is lacking. If Astbury and Davies, Cox and Brown, Meyer and Misch, Haworth and others assume an unstrained angle of $110^{\circ}$, they may do so in good company-but Pauling ${ }^{8}$ as well as Peirce must be excluded from the company.

The variation of the oxygen angle shows it to be deformable. If one sees an elastic thread under an evident load, it is no speculation to assume that its unstrained length is less than the observed length. In $\mathrm{H}_{2} \mathrm{O}$, the oxygen angle is $105^{\circ}$ and it is distended by the ionic character of the $\mathrm{H}$ fields. This ionic character is less in $\mathrm{F}_{2} \mathrm{O}$ and the angle is less, $100^{\circ}$. In $\mathrm{H}_{2} \mathrm{~S}$, the greater separation of the $\mathrm{H}$ fields means less repulsive stress and the angle is $92^{\circ}$. (These are the values quoted by Pauling ${ }^{8}$.) When large groups are attached to the two bonds, the angle is correspondingly large, attaining $130^{\circ}$ and more in the diphenyl ethers ${ }^{2,10}$. All this is in perfect accord with Pauling's theory, that the oxygen bonds arise from $p$ electrons and are unstrained at $90^{\circ}$.

It is true that atoms of the appropriate size to enforce an angle of some $110^{\circ}$, CI (in $\mathrm{Cl}_{2} \mathrm{O}$ ) and $\mathrm{C}$, are not infrequently involved, but this obviously strained angle of a soft atom is not to be confused with the tetrahedral angle of the hard and symmetrical carbon atom. The latest figures on the aliphatic ethers give values of $110^{\circ}$ or less ${ }^{11}$, and these are clearly strained by an otherwise unbalanced repulsion between the closely held carbon atoms. Dioxane $\left(110^{\circ}\right)^{12}$ looks more like a pyranose ring but, by symmetry, the field round each oxygen atom must be closely similar to that in dimethyl ether. When the two carbon neighbours of the oxygen are held also by a line of three carbon atoms, these can take some of the stress from the oxygen bonds and even impose an opposite strain, if there be a minimum of free energy when a line of carbon atoms is co-planar.

The position seems to be, therefore, that the unstrained angle is $90^{\circ}$ and the strain is unknownso the simplest assumption is the strainless form, as given in my note. The fact that it fits so neatly into the cellulose lattice commends it, but I would be the last to claim for the resultant structure any status beyond that of a tentative, approximate speculation, possibly useful as a working hypothesis to correlate the general body of data: and this is all that I would allow to any detailed crystal structure ascribed to a macromolecular fibre.

The parameters are given to $0.01 \mathrm{~A}$. because they express the geometrical consequences of assumptions reasonably defined to that degree of accuracy. This basic, strainless form may later be strained to accord with direct evidence still to be found, but it seems worthy of inclusion in 'trial and error' studies. To that end, it was offered through the speedy channel of the correspondence to Nature.

F. T. PeIRCE.

British Cotton Industry Research Association, Shirley Institute, Didsbury, Manchester.

\footnotetext{
1 Peirce, Nature, 158, 586 (1944).

Astbury and Davies, Nature, 154, 84 (1944).

Brown, C. J., Ph.D. Thesis (Birmingham, 1939).

- Cox and Jeffery, Nature, 148, 894 (1939).

Meyer and Misch, Helv. Chim. Acta, 20, 894 (1937).

Cox, Nature, 154, 84 (1944)

Cox, Goodwin and Wagstaff, J. Chem. Soc., 1495 (1935)

- Pauling, "Nature of the Chemical Bond", p. 78 et seq. (1939).

- Sutton and Coop, J. Chem. Soc., 1869 (1938).

10 Hampson, Farmer and Sutton, Proc. Roy. Soc., 143, 147 (1933).

11 Sutton, Ann. Rep. Chem. Soc., 72 (1940).

19 Glasstone, Ann. Rep. Chem. Soc., 84 (1936).
} 